\title{
QUESTÕES ÉTNICO RACIAIS NO CURRÍCULO E NAS PRATICAS DOS PROFESSORES DE GEOGRAFIA DE UM COLÉGIO DE REFERENCIA ${ }^{1}$
}

\author{
Emmanuel Nascimento de Carvalho de Brito $^{2}$ \\ Edmilton Amaro da Hora Filho ${ }^{3}$ \\ Auxiliadora Maria Martins da Silva ${ }^{4}$
}

Resumo: Este é uma pesquisa documental e um levantamento qualitativo que objetiva descrever como a questões étnico raciais previstas na lei 10.639/2003 e nas Diretrizes Curriculares Nacionais para a Educação das Relações Étnico-Raciais e para o Ensino de História e Cultura Afro-Brasileira e Africana são abordadas no currículo e nas praticas dos professores de Geografia de um colégio de referencia. De forma especifica objetiva: a) Caracterizar o campo de pesquisa indicando aspectos sobre o colégio que serviu base para a realização do estudo; b) Investigar a presença das questões étnico raciais previstas na lei 10.639/2003 e nas Diretrizes citadas no objetivo geral dentro dos documentos curriculares do Colégio; c) Avaliar como este conteúdo é trabalhado pelos professores de Geografia do colégio. Para tanto, analisou documentos curriculares do colégio em busca de elementos que atendam as exigências da lei 10.639/2003 e das Diretrizes acima citadas, assim como, entrevistou todos os professores da disciplina de Geografia, buscando compreender como ocorrem as práticas curriculares relativas as questões étnico raciais nas aulas da disciplina. Conclusivamente, tratar das questões étnico raciais é uma opção, uma vez que, os documentos curriculares não retratam essa necessidade. Porém, foi observado que os professores do colégio trouxeram boas práticas e a diversidade deles permitiu concluir que o processo de abordagem das questões étnico raciais se da não apenas por uma questão de afinidade, mas, por uma serie de fatores como o conhecimento, as experiencias pessoais e a formação.

Palavra-chave: questões étnico raciais; geografia; práticas curriculares; colégio de referencia.

1 Trabalho realizado pelo aluno Emmanuel N. C. Brito e orientado pelos docentes Edmilton A. H. Filho e Auxiliadora M. M. Silva para pontuar as disciplinas "PPP3: Praticas Curriculares na escola e na sala de aula” e "Fundamentos do Ensino de Geografia” do Curso de graduação em Pedagogia da UFPE 2019.2.

2 Graduando em Pedagogia pela Universidade Federal de Pernambuco (UFPE).

3 Graduado em Pedagogia pelo Centro Universitário Internacional (UNINTER), graduado em Geografia pela Universidade Federal de Pernambuco (UFPE), Mestre em EDUCAÇÃO pela Universidade Federal de Pernambuco (UFPE) e Doutorando em Educação pela Universidade Federal de Pernambuco (UFPE).

4 Graduada em Pedagogia pela Universidade Católica de Pernambuco (UNICAP), Mestra em Ensino das Ciências pela Universidade Federal Rural de Pernambuco (UFRPE) e Doutora em Educação pela Universidade Federal de Pernambuco (UFPE). 


\section{INTRODUÇÃO}

Este é uma pesquisa documental e um levantamento qualitativo que objetiva descrever como a questões étnico raciais previstas na lei 10.639/2003 e nas Diretrizes Curriculares Nacionais para a Educação das Relações Étnico-Raciais e para o Ensino de História e Cultura Afro-Brasileira e Africana são abordadas no currículo e nas praticas dos professores de Geografia de um colégio de referencia.

De forma especifica objetiva: a) Caracterizar o campo de pesquisa indicando aspectos sobre o colégio que serviu base para a realização do estudo; b) Investigar a presença das questões étnico raciais previstas na lei 10.639/2003 e nas Diretrizes Curriculares Nacionais para a Educação das Relações Étnico-Raciais e para o Ensino de História e Cultura AfroBrasileira e Africana dentro dos documentos curriculares do Colégio; c) Avaliar como este conteúdo é trabalhado pelos professores de Geografia do colégio.

Para tanto, utiliza da analise documental no PPPI e ementas de Geografia em busca de citações sobre as questões étnico raciais na formação e composição do currículo e praticas curriculares do colégio. Sendo também, aplicados formulários com os professores da disciplina de Geografia buscando entender como este processo veem sendo praticado.

Esta pesquisa se justifica pela importância de compreendermos como as questões étnico raciais são trabalhadas em um colégio considerado referencia diante das avaliações institucionais de âmbito nacional, uma vez que, isso pode nos dar uma perspectiva de como pode ser e como esta a nossa prática curricular a respeito do tema.

Portanto, esta pesquisa tem como principal questão: Como o currículo e os professores de Geografia de um colégio de referencia abordam as questões étnico raciais previstas na lei 10.639/2003 e nas Diretrizes Curriculares Nacionais para a Educação das Relações ÉtnicoRaciais e para o Ensino de História e Cultura Afro-Brasileira e Africana?

Partindo da hipótese de que o conteúdo é bem trabalhado abrangendo vários aspectos das culturas brasileiras. Esta hipótese surge da ótimas avaliações do colégio em âmbito nacional e da construção ideológica desta escola como um lugar também de formação moral que prepara os alunos para os diversos contextos sociais.

\section{REFERENCIAL TEÓRICO}

Segundo Moreira (2009) a Geografia é um campo de estudo que investiga o homem e suas relações com a terra diante da incessante busca do ser humano pela felicidade, que, será descrito por meio do tempo e do espaço. Porém, para que seja melhor compreendida, esta relação deve ser localizada, isto e este acontecimento tem uma origem e uma amplitude 
espacial, portanto, destacamos aqui a perspectiva de Almeida e Passini (2002), que trabalharam com cartografia e ressaltaram a importância da habilidade de ler mapas para a disciplina devido ao fato de que o mapa é a representação de um determinado espaço real.

Diante desta caracterização da Geografia Cavalcanti (2001) ressalta o como a área costuma ser vista como receitas prontas "um conhecimento já construído" e neste sentido ainda considera a Geografia como uma das principais responsáveis pelo cruzamento entre a escola e a cultura, caracterizando a escola como desenvolvedora de cultura.

Sendo a escola um campo voltado para o desenvolvimento da cultura e a Geografia intimamente interligada a este processo de desenvolvimento, podemos compreender o como as questões étnico raciais estão entrelaçadas com a disciplina diante do fato de que o racismo é fruto da sociedade enquanto a geografia estuda esta sociedade.

Porém, a cultura afrodescendente perpassa por diversas dificuldades, como relatado por Fanon (2008), o negro diante das pressões sociais e dos processos de colonização que desvalorizam sua cultura acaba por não reconhecer a necessidade de reafirmar suas origens enquanto identidade e cria um complexo de inferioridade que torna o preconceito "natural".

Diante destas questões, destacamos a necessidade da geografia intervir, tratando a cultura negra e sua amplitude, isto é, por meio do espaço, afinal, como Almeida e Passini (2002) destacam, o mapa se torna importante no ensino de Geografia no momento em que tem por foco o espaço, logo, o mapa se torna um instrumento de investigação e verificação.

Esta investigação espacial localiza, torna material a percepção de que as manifestações culturais afrodescendentes acontecem e possuem amplitude geográfica, consequentemente, valorizando este povo e evitando a alienação cultural citada por Fanon (2008) que é um processo de recusa da sua cultura decorrente da colonização de um povo que construí um complexo de inferioridade coletivo nos seres daquele grupo.

Como Cavalcanti (2001), propõe o trabalho com textos, poesias, musicas, vídeos, filmes, estes os quais, hoje se tornam cada vez mais acessíveis e consequentemente utilizáveis durante as aulas e a questão étnico racial tem uma amplitude Geográfica, podemos portanto, trabalhar considerar estas midicas cmo o cinema, as musicas e as poesias africanas.

É por estas questões que surgiu a lei 10.639/2003 determina a obrigatoriedade contemplar a cultura negra em todo o currículo do ensino básico. (BRASIL, 2003) neste sentido é originado as Diretrizes Curriculares Nacionais para a Educação das Relações Étnico-Raciais e para o Ensino de História e Cultura Afro-Brasileira e Africana, um documento que delimita como a temática deve ser abordada. (BRASIL, 2004) 
Cavalcanti (2001) defende a inclusão da Geografia no currículo como uma disciplina que deve contemplar o espaço como dimensão da pratica social e cultural. Diante das questões étnico raciais estas praticas podem ser compreendidas como o desenvolvimento da consciência politica e histórica da diversidade, o fortalecimento de identidades e de direitos e ações educativas de combate ao racismo e a discriminações. (BRASIL, 2004).

As diretrizes ressaltam a necessidade de enfrentarmos esteriótipos físicos e a desvalorização da cultura afrodescendente e destaca que devido as ideologias de branqueamento alguns negros podem acabar reproduzindo o preconceito do qual são vitima (BRASIL, 2004). Algo reconhecido por Fanon (2008) quando de forma metafórica ele chega ao ponto de afirmar que um negro que vá para Paris tem mudanças quase genéticas em seus fenótipos sofrendo uma espécie de mutação definitiva e absoluta devido ao fato de comumente adotar os habitos desta cultura em detrimento da sua própria.

Considerando todos os pontos acima levantados destaco: O combate ao racismo é papel de todos os professores independente do seu pertencimento étnico-racial e da disciplina em que atua. (BRASIL, 2004). Portanto, se fazendo necessário compreender e praticar todos os aspectos elencados neste referencial tanto na pesquisa como na pratica docente.

\section{METODOLOGIA}

Esta é uma pesquisa documental qualitativa, uma vez que, analisou documentos que não receberam tratamento analítico antes e expressa seu resultado sem o uso de números, mas, compreendendo as qualidades contidas nos dados da pesquisa. (GIL, 2002). destacamos também que esta pesquisa é um levantamento, pois, realiza uma interrogação direta com as pessoas cujo comportamento desejamos conhecer (PRODANOV; FREITAS, 2013).

Para tanto, serão utilizados 2 instrumentos de pesquisa: a) Analise documental em busca de elementos nos documentos curriculares que atendam as exigências da lei 10.639/2003 e das Diretrizes Curriculares Nacionais para a Educação das Relações Étnico-Raciais e para o Ensino de História e Cultura Afro-Brasileira e Africana; b) Entrevista com os professores da disciplina de Geografia, buscando compreender como ocorrem as práticas curriculares relativas as questões étnico raciais nas aulas da disciplina.

Visando manter o privacidade dos docentes, não será exposto o nome, sexo, data da entrevista, serie de atuação ou escola em que trabalha. As únicas informações pertinentes a esta pesquisa são: a) Se trata de uma escola de referencia com nota alta no IDEB; b) Todos os professores entrevistados pertencem a instituição e lecionam a disciplina de Geografia. 


\subsection{Método de entrevista}

Como já informado, a entrevista será estruturada, porém, destaco aqui uma peculiaridade do modelo de entrevista aplicado nesta pesquisa. Toda e qualquer informação será simultaneamente analisada e reescrita durante a entrevista, questionando se a forma como foi expressado retrata o real sentido relatado pelo entrevistado. Isto é, conforme forem feitas as perguntas, os entrevistados irão responder, consequentemente, o entrevistador colocará com suas palavras o que foi dito, perguntando se expressa o que o entrevistado quis dizer.

\subsection{Roteiro da pesquisa}

Inicialmente foram solicitado os documentos curriculares e ementas de Geografia do colégio, enquanto as visitas foram realizadas da seguinte forma: na $1^{\mathrm{a}}$ e $2^{\mathrm{a}}$ visita focamos em caracterizar os aspectos físicos, projeto politico pedagógico, funcionamento administrativo da escola e concepção de educação e avaliação da escola. Delimitar quais são os documentos curriculares da escola, obter as ementas da disciplina de geografia e analisar a existência do conteúdo previsto na lei diretrizes nos documentos curriculares. Da $3^{\mathrm{a}}$ ate a $6^{\mathrm{a}}$ visita, tivemos o objetivo de realizar a analise dos documentos curriculares, realizar as entrevistas com os professores e concluir a pesquisa. As perguntas constam no apêndice A desta pesquisa.

\section{ANALISE DOS DADOS}

Para melhor organização do trabalho, dividiremos os dados e analise da pesquisa em 2 subseções: informações da instituição e entrevistas com os professores do colégio.

\subsection{Informações da instituição}

Esta sessão contempla as informações advindas da instituição onde a pesquisa foi realizada, portanto, contempla a caracterização do campo de pesquisa e as analises referentes ao projeto politico pedagógico da escola e das ementas de geografia.

\subsubsection{Caracterização do campo de pesquisa}

Possui uma boa estrutura com uma área relativamente grande possuindo um bom espaço para lanche e para intervalo. Possui uma quadra esportiva medida pelo comprimento de um braço do pesquisador ate seu outro braço, resultando em uma largura interna equivalente a 21 vezes a unidade de medida utilizada, neste caso, cerca de 40 metros.

O colégio esta de reforma, mas, a maior parte das salas parecem estar em bom estado possuindo quadros de vidro, ar condicionado e projetores. A biblioteca foi deslocada para o 
térreo e as obras estão sendo reorganizadas. Na perspectiva da bibliotecária o colégio esta crescendo e se tornando mais autônomo. Ainda na questão da estrutura, o colégio ainda não possui rampas para cadeirantes subirem ao primeiro andar mas curiosamente o bebedouro é adaptado para cadeirantes.

A escola possui Ensino Fundamental II e Ensino Médio, não tendo Educação de Jovens e Adultos ou Ensino fundamental I e Educação Infantil. Muitos dos professores do colégio possuem mestrado e doutorado e é reconhecido como um campo de pesquisa que incentiva a inovação pedagógica e teste de práticas inovadoras na educação.

O colégio é administrado por setores que dividem as tarefas, existe um setor que foca na aprendizagem, outro na organização de documentos, outro no recebimento de estágios, outro no recebimento de autorização de pesquisas cientificas e assim por diante. Estes setores podem ser melhor compreendidos quando consultando a Projeto Politico Pedagógico (PPP) do colégio que na instituição recebe o nome institucional ao fim originando o PPPI.

Este colégio possui nota alta no IDEB e características bem diversas sobre a formação. Há disciplinas consideradas eletivas as quais os alunos possuem uma carga podendo pagar conforme as disciplinas eletivas que desejar cursar, projetos de extensão, monitoria, eventos, órgãos representativos como grêmio estudantil e participação dos alunos, professores, técnicos e dos pais dos alunos na construção do PPPI e tomada de decisões do colégio.

Alguns funcionários quando questionados relataram que teve um aumento de negros quando o colégio abriu para cotas, mas, acreditam ter quantidade menor do que brancos. Um deles considera visível o aumento de negros, mas, muito subjetivo. Neste sentido, por meio de observação, aparentou que a cada 5 alunos: 2 são brancos, 2 são pardos e 1 é negro.

\subsubsection{PPPI (Projeto Politico Pedagógico Institucional)}

Muitos dos elementos abordados durante a introdução no que diz respeito ao funcionamento do colégio e características gerais estão descritos neste documento. Buscando pelo termo "étnic" foi encontrado apenas um resultado "perda da identidade étnica e cultural"

o treco aborda sobre o contexto social atual e as crescentes desigualdades existes.

O termo "racial" e "racismo" não retornaram nenhum resultado não estando presentes no texto. O numero "10639" ou "10.639" referente a lei que determina a obrigatoriedade de abordar as questões étnico raciais também não retornou resultados.

Quando se tratando do termo "negr" foi encontrado "negros" e "escravidão negra africana" em um trecho que retrata sobre os tipos de preconceitos e afirma que as cotas são uma compensação pelos processos da escravidão negra africana. 
Observando as temáticas abordadas um dos tópicos aborda os princípios formativos do colégio apontando para a concepção de mundo, sociedade, ser humano e educação escolar. Neste sentido, compreende a sociedade enquanto fortemente transformada diante do surgimento das novas tecnologias, o ser humano como um cidadão participativo, criativo, critico, justo que se adapte as transformações sociais e conviva em sociedade, quanto a educação escolar como uma instituição justa e democrática que promova uma formação de seres humanos conforme a concepção apresentada.

Quando se tratando da temática do currículo retrata os diversos aspectos incluídos no currículo aos quais já foram retratados na caracterização da escola, como as eletivas, monitorias, projetos de extensão e eventos realizados pela escola.

Conclusivamente o texto aborda muito sobre respeitar as diversidades, mas, pouco se aprofunda sobre o que exatamente deve ser feito, neste sentido, apontando vez ou outra para seus objetivos formativos sem necessariamente detalhar o motivos e as questões por trás destas demandas declaradas no projeto.

\subsubsection{Ementas de Geografia}

Em todas as etapas do ensino a disciplina de Geografia possui 120 hora anuais e 3 horas semanais. No $6^{\circ}$ ano existem poucos conteúdos humanos, no $7^{\circ}, 8^{\circ}$ e $9^{\circ}$ ano, potenciais conteúdos para trabalhar a dimensão das questões étnico raciais aparecem nas ementas sem necessariamente se referir à estas questões.

Da $1^{\text {a a }} 3^{\mathrm{a}}$ serie do ensino médio os conteúdos se tornam mais densos, englobando muito dos anteriores e novamente nenhuma menção aos termos "cultura", "étnic", "racismo", "racial", "africa" ou perspectiva de trabalhar os preconceitos, logo, possibilitando apenas explorar á temática étnico racial de acordo com o desejo do docente responsável.

\subsection{Entrevista com os professores do colégio}

Para compreender a relação da formação recebida com os relatos apontados organizamos os professores na ordem de conclusão das suas licenciaturas em geografia, do mais antigo ao que teve a formação mais recente.

\subsubsection{Professor $1-1993$}

Este docente preferiu responder as questões por e-mail, portanto, o procedimento metodológico não foi aplicado e a apresentação dos dados será feita de forma diferenciada. Para fins de adaptação, os dados do docente serão apresentados antecedidos da pergunta 
realizada e serão mantidos integralmente e fieis as respostas recebidas, a fim de que, seja mostrado aquilo a qual o profissional permitiu ser publicado.

Quando perguntado qual é a concepção de currículo esclareceu: "Concordo com o Saviani quando diz "consiste em organizar o conteúdo e desenvolvê-lo didaticamente". Porém, complemento que, na prática, temas transversais devem ser explorados e, assim, enriquece-se o conteúdo e, consequentemente, o currículo."

Em relação a lei 10.639/2003 afirmou se tratar da história da África nas escolas. Tratando de sua etnia respondeu "Quando nasci, em 1970, as pessoas olhavam pra você e registravam na Certidão: branca. Mas não me considero como tal. Sou apenas uma brasileira que tem ancestrais europeus, afrodescendentes e índios, até onde sei."

Sobre ter contato com questões étnico raciais durante sua formação afirmou "Não. Eu me formei em 1993 na Graduação e não se falava a respeito na época.”. Sua opinião sobre a relação entre as questões étnicos raciais e a geografia é "Com toda franqueza, não trabalho com esse tema, portanto, não posso responder de forma ampla. O que posso pensar de forma associativa é quanto à distribuição geográfica da diversidade étnica existente no planeta.”.

Quando perguntada sobre a importância de abordar as questões étnico raciais em sala de aula afirmou "Muito importante. Mas não é fácil. Necessita-se de muito conhecimento a respeito, isenção científica nas concepções, discernimento para conduzir os debates e respeito às diferentes opiniões.”. Se tratando de abordar estas questões durante as aulas de geografia respondeu "Não abordo.” Justificando "Tenho ensinado Geografia Física.”. Relativo a como aborda refirmou "Como disse, não abordo." e sobre exemplos do tema relatou "Mas se surgir a discussão, procuro respeitar as opiniões que surgirem.”.

\subsubsection{Professor $2-1994$}

Considera o currículo abstrato, pois, relata estudo tardio dentro do curso de formação. São os componentes que o professor precisa contemplar para formar o estudante, considera que falta conhecimento para expressar melhor. Conhece a lei 10.639/2003, afirmando que se trata do ensino de conteúdos africanos e a influencia deles no ensino básico que depois foi ampliada para ensino dos da cultura indígena.

Se considera branca e não teve contato com questões étnico raciais durante a formação. $\mathrm{Na}$ sua opinião a geografia se relaciona com as questões étnico raciais quando trabalha o processo de migração, as disputas territoriais, os reinos africanos, a troca de mercadorias e outros deslocamentos territoriais. 
Para o docente, é importante abordar questões étnico raciais na aula porque considera fundamental para que as pessoas não tratem os outros mal. relatando que conviveu com um parente familiar muito próximo que era extremamente racista e considera isso uma violência pessoal, lutando para se tornar o oposto disso. Sua historia o motivou a desenvolver a humanidade em seus alunos diante do preconceito violento que observou.

Aborda as questões étnico raciais nas aulas de Geografia para que as pessoas não tratem as outras mal dando como exemplos: a) debates, filmes e leituras. b) debate sobre o discurso "eu tenho um sonho" de Martin Luter King.

Como este professor foi responsável por uma discina chamada "africa" e um projeto de extensão relacionado também com a cultura africana, 2 novas perguntas foram adicionadas à entrevista do docente, visando compreender qual foi atuação da disciplina e do projeto: a) Qual foi o assunto da disciplina "africa"? Possui relação com a geografia? b) Pode dar exemplos de atuação do projeto "africa..."? Possui relação com a geografia? Devido ao sigilo do colégio mantivemos o nome do projeto oculto, afim de evitar identificações.

A disciplina inicialmente trabalhava filmes de temáticas africanas, depois, trouxe filmes do cinema africano e textos sobre questões étnico raciais onde os alunos produziram artigos científicos, originando, um livro com o mesmo titulo do projeto de extensão. Atualmente a disciplina foi assumida por docentes de historia. Algumas vezes a disciplina tratava das questões étnicos raciais dentro da geografia, citando como exemplo o filme "um grito de liberdade" que retrata o Apartheid.

Criou um projeto porque era ausente no colégio, então, buscou conhecimentos cursando disciplinas em historia, sociologia e antropologia. O projeto se tratava de um curso de formação que durava 1 mês e tinha como publico alvo comunidade acadêmica e professores de escola publica. Alunos da escola do $9^{\circ}$ eram monitores e eram preparados para apresentar a temática do projeto para o publico. Era questionado o fato de não ter alunos negros apresentando no projeto, justificável, pela pouca presença da etnia dentro do colégio na época por não ter cota.

Não imagina o projeto sendo realizado hoje devido ao deficit das turmas atuais, principalmente, em relação aos alunos cotistas, considerando pesado tratar de uma abordagem extra curricular. Afirma que o homem transforma o meio, relacionando o projeto com o conhecimento geográfico. Cita como exemplo do filme Hotel Ruanda, que retrata uma guerra entre 2 etnias que eram próximas, motivada pelos colonizadores. 


\subsubsection{Professor $3-2008$}

Considera o currículo uma padronização que a instituição faz sobre os valores, conteúdos e pratica pedagógica. Não conhece a lei 10.639/2003 pelo numero, mas reconhece pelo seu conteúdo. Se considera pardo e afirma que teve contato com as questões étnico raciais durante a formação quando estudou demografia, mas sem profundidade.

$\mathrm{Na}$ sua opinião a Geografia se relaciona com as questões étnicos raciais em tudo: definição de valores, convivência de povos, reconhecimento histórico de alguns em detrimento de outros, a valorização da historia, territorialidade e as relações econômicas, demográficas e sociais. Considerando importante abordar estas questões na sala de aula para reduzir as desigualdades.

Afirma que aborda as questões étnicos raciais durante as aulas de geografia porque faz parte do currículo e é uma necessidade social e global. Neste sentido, citando como exemplos:

a) Atividade sobre senso demográfico, onde a cor é contemplada e o objetivo se da por analisar os resultados percentuais encontrados gerando debates sobre os resultados e as relações sociais. b) Trabalhar com o catalogo de cores de pantone, que se trata uma tabela com diversas cores de pele diferentes para que as pessoas possam se identificar, fazendo um paralelo com a cor previamente declarada.

\subsubsection{Professor $4-2011$}

Compreende o currículo como uma estrutura guia para o desenvolvimento da disciplina. Entende 2 vertentes: vertical a qual determina uma pratica restritiva e uma mais horizontal que permite participar na formação do currículo, sendo algo mais construtivista e democrático, envolvendo pais, alunos, gestão, equipe pedagógica e professores. Dizendo que a escolha vai depender muito do pais, do estado e momento histórico.

Desconhece a lei 10.639/2003, se considera negro e teve conta com as questões étnico raciais durante sua formação, indo a campo e visitando comunidades quilombolas tendo contato com as manifestações culturais religiosas, folclóricas, vivencias e historias.

Para ele a Geografia estuda a sociedade, o trabalho, a territorialidade. A inclusão das questões étnicos raciais conectando a produção espacial é o que possibilita trabalhar ela dentro da Geografia. Considera importante abordar as questões étnico raciais em sala de aula para formar cidadãos criticos e conscientes que busquem derrubar preconceitos e velhos paradigmas da sociedade.

Aborda as questões étnicos raciais durante as aulas de geografia porque precisa trabalhar o conteúdo proposto pelo currículo e devido a importância que o tema tem para o 
Brasil por causa da diversidade cultural, étnica, econômica, social e também ao fato do preconceito racial ser bastante presente em nossa sociedade.

Reconhece varias formas de abordar o tema em sala de aula, mas, costuma distribuir a temática nas diversos campos de estudo da geografia. Como exemplos relatou: a) aula de demografia na distribuição populacional, usou mapas, imagens, vídeos, musicas, noticias em jornais, acontecimentos histórico, infográficos, índices e dados sociais. b) Documentário: de onde venho, não existe mais, associando o preconceito ao estereotipo árabe as questões étnicos raciais. c) trabalho com a filosofia Unbutu que retrata o modo de ser de uma parte do povo africano e a sua relação com a economia, produção cultural e sociedade. d) Aula de agricultura que mostrava as praticas agroecológicas dos indígenas e quilombolas sobre o como podemos aprender com eles.

\subsubsection{Professor 5 - 2014}

Compreende o currículo como habilidades e conteúdos que devem ser trabalhados dentro da escola. Desconhece a lei 10.639/2003 apenas o nome mas compreende o proposito. Se considera branco. E teve contato com as questões étnico raciais durante sua formação em disciplinas que contemplavam conteúdos sobre culturas principalmente africanas e quilombolas.

Para ele a Geografia esta relacionada aos aspectos físicos, culturais e religiosos, consequentemente, consolidando a relação entre questões étnico raciais e a Geografia. Considerando de grande importância abordar estas questões, uma vez que, nos somos oriundos de culturas e religiões diversas, que se misturaram, construindo esta cultura que nos vivenciamos e que ainda temos muitos preconceitos na busca de superá-los.

Aborda as questões étnicos raciais durante as aulas de Geografia para superar os preconceitos estabelecidos pela sociedade e meios vivenciados pelos alunos. Citando como exemplo: Abordar na questão religiosa, cultural, hábitos, vestimentas, cultivo. Considera as questões étnicos raciais atreladas a todas as áreas da Geografia.

\section{CONCLUSÕES}

Pelo caráter prioritariamente administrativo do PPPI é compreensível que não aprofunde nas questões sobre as quais o colégio irá tratar, sempre tendo uma visão superficial sobre a existência do processo para acusar que algo tem que ser feito. As ementas foram ainda menos contemplativas sobre as questões étnico raciais, contendo nenhuma especie de referencia sobre a temática e deixando ao cargo do docente decidir se irá abordar ou não. 
Quando se tratando das entrevista, o primeiro ponto é que quanto mais antiga a formação menos foi abordado as questões étnico raciais durante as licenciaturas de Geografia, neste sentido, foi visível por parte dos docentes mais recentes maior familiaridade com a temática. A cor não foi um fator determinante nas praticas, ao ponto que o docente responsável pelo projeto de extensão e a disciplina africa é branco e possui formação antiga.

Este docente, o professor 2, decidiu trabalhar esta temática não devido a sua formação ou conhecimentos, mas, devido as experiencias vividas as quais motivou a buscar aprofundar estas questões e trabalhá-las em sala de aula. Acerca dos conhecimentos relativos a Geografia e as questões étnico raciais apenas o professor 1 relatou não trabalhar as questões étnico raciais devido ao fato de ter por foco a Geografia física.

Logo, reafirmo que o combate ao racismo é papel de todos os professores independente do seu pertencimento étnico-racial e da disciplina em que atua. (BRASIL, 2004) concluindo que o processo de abordagem das questões étnico raciais se da não apenas por uma questão de afinidade, mas, por uma serie de fatores como o conhecimento, as experiencias e a formação.

\section{REFERENCIAS}

ALMEIDA, Rosângela Doin de; PASSINI, Elza Yasuko. O espaço geográfico: ensino e representação. 12 ed. São Paulo: Contexto, 2002. p. 07-90

BRASIL. Ministério da Educação/Secad. Diretrizes curriculares nacionais para a educação das relações étnico-raciais e para o ensino de história e cultura afro-brasileira e africana na educação básica. 2004.

BRASIL. Presidência da República. Lei 10.639 de 9 de janeiro de 2003. Altera a Lei 9.394, de 20 de dezembro de 1996, que estabelece as diretrizes e bases da educação nacional, para incluir no currículo oficial da Rede de Ensino a obrigatoriedade da temática "História e Cultura Afro-Brasileira", e dá outras providências.

CAVALCANTI, Lana de Souza. Geografia escolar e procedimentos de ensino numa perspectiva socioconstrutivista. In: CAVALCANTI, Lana de Souza. Geografia e práticas de ensino. Goiânia: Alternativa, 2002. p.71-100.

GIL, Antônio Carlos. Como classificar as pesquisas? 2002.

FANON, Frantz. Pele negra, máscaras brancas. 2008.

MOREIRA, Ruy. O QUE É GEOGRAFIA. $2^{\circ}$ ed, 2009.

PRODANOV, Cleber C.; FREITAS, Ernani C. de. Metodologia do trabalho científico:

Métodos e Técnicas da Pesquisa e do Trabalho Acadêmico. Novo Hamburgo: Feevale. 2 ed. 2013. 


\section{APÊNDICE A - ENTREVISTA COM OS PROFESSORES DE GEOGRAFIA}

Informações sobre a pesquisa: Levando em consideração que apenas a disciplina de atuação é importante nesta pesquisa, todos os dados pessoais serão mantidos em sigilo e não haverá identificação do nome, serie em que atua, data da realização da entrevista ou colégio em que exerce a profissão. $O$ procedimento de verificação dos dados será realizado simultaneamente ao o que for dito e conforme for relatado pelo entrevistado, será perguntado se a forma de escrita expressa o real sentido da fala e se permite a publicação.

1- Qual é a sua concepção de currículo?

2- Você sabe o que é a lei 10.639/2003?

3- Você se considera de qual etnia?

4- Você teve contato com questões étnico raciais durante sua formação?

5- Na sua opinião, qual é a relação entre as questões étnicos raciais e a geografia?

6- Na sua opinião, qual é a importância de abordar as questões étnico raciais em sala de aula?

7- Você aborda as questões étnicos raciais durante as aulas de geografia? Porque?

8- Se sim, como você aborda? Pode dar exemplos de aulas com ou sobre o tema? 